Revista Eletrônica em Gestão, Educação e Tecnologia Ambiental Santa

Maria, v. 20, n. 1, jan.-abr. 2016, p. 50-61

Revista do Centro de Ciências Naturais e Exatas - UFSM

ISSN : 22361170

REGET/UFSM

Revista Eletrônica em Gestão, Educação e Tecnologia Ambiental

\title{
Gestão ambiental e responsabilidade social: Uma perspectiva das ações sustentáveis praticadas por uma empresa do ramo de agronegócios
}

Environmental management and social responsibility: A perspective of sustainable actions carried out by a company in the field of agribusiness

\section{Shaiane Caroline Kochhann ${ }^{1}$, Ana Elizabeth Moiseichyk², Maíra Nunes Piveta ${ }^{1}$, Sandra Leonara Obregon ${ }^{1}$}

1Universidade Federal de Santa Maria

2 Universidade Federal de Santa Maria - Campus de Palmeira das Missões

\begin{abstract}
Resumo
A adoção de práticas socioambientais constitui a incorporação de um "papel social" por parte das empresas levando-se em consideração que as mesmas são capazes de influenciar e transformar um contexto local por meio de pequenas atitudes inseridas no dia a dia organizacional. Além de gerar diversas melhorias, as adoções de atitudes sociais e ambientais pelas organizações promovem uma diferenciação das demais empresas, segundo o contexto competitivo do mercado, pois hoje em dia, o cliente procura mais do que um produto. Este estudo buscou, portanto, verificar a importância e a aplicabilidade da Gestão Ambiental aliada às ações de Responsabilidade Social realizadas por uma pequena organização pertencente ao ramo de agronegócios. A coleta de dados que permitiu a concretização deste estudo deu-se por meio da aplicação de um instrumento de pesquisa a uma amostra de 203 pessoas divididas entre funcionários, fornecedores, clientes e sociedade. Quanto aos resultados obtidos com a aplicação da pesquisa, evidenciou-se que a empresa estudada trata com muita importância as questões relacionadas à gestão socioambiental. A mesma já possui em vigência, de acordo com os entrevistados, algumas ações que contemplam o tema podendo, porém, incrementar ainda mais a sua atuação socialmente responsável.
\end{abstract}

Palavras-chave: Gestão Ambiental. Responsabilidade Social. Práticas Organizacionais.

\begin{abstract}
The adoption of environmental practices is the incorporation of a "social role" by companies taking into consideration that they are able to influence and transform a local context through small attitudes embedded in everyday life. Besides generating several improvements, the adoption of social and environmental attitudes by the organizations promote differentiation of other companies, according to the competitive market context, because nowadays, the client looks for more than one product. This study sought, Therefore, check the importance and applicability of environmental management combined with the Social responsibility actions carried out by a small organization in the field of agribusiness. Data collection that allowed the achievement of this study came about through the application of a survey instrument to a sample of 203 people divided between employees, suppliers, customers and society. The results obtained with the application of the research, it was evidenced that the company studied deals with very important social and environmental management issues. The same has already in effect, according to the interviewees, some actions that contemplate the theme and may, however, increase its socially responsible action.
\end{abstract}

Keywords: Environmental Management. Social Responsibility. Organizational Practices. 


\section{Introdução}

O consumo consciente e ecologicamente correto diz respeito à forma como nos posicionamos diante das ocasiões de aquisição de produtos e serviços onde estamos constantemente expostos devido às nossas necessidades fisiológicas, pessoais e sociais. De acordo com Ribeiro e Veiga (2011, p.3), "o aumento do aquecimento global e a iminência de catástrofes naturais dele decorrentes, vem aumentando a preocupação com a preservação do meio ambiente nas últimas décadas". Nesta perspectiva, entende-se que tais problemas ambientais foram alavancados em virtude do consumo acelerado, o qual se inicia por meio da forte onda de industrialização provocada por necessidades capitalistas de maximizar retornos financeiros e não considerar os impactos ambientais causados.

Corroborando com o exposto anteriormente, Milani Filho, Corrar e Martins (2009) ressaltam que no panorama mundial os problemas sociais e ambientais existentes são provenientes da insuficiência ou ausência de políticas governamentais que de fato mostrem-se eficientes e capazes de prezar pelo bemestar coletivo. Diante disto, surge um movimento impulsionado pela sociedade em prol da cobrança de medidas que faz com que as empresas sintam-se pressionadas, vindo a adotar medidas que sejam social e ambientalmente corretas para a condução dos seus negócios. Esta preocupação oriunda da população e transmitida às organizações, importantes membros da sociedade, fez com que os recursos e esforços investidos nas práticas de responsabilidade social e ambiental tenham ganhado maior notoriedade nos últimos tempos. (COUTINHO; MACEDO-SOARES, 2002).

Nesse sentido, Kirschner (2006) relata em seus estudos que muitas organizações vêm se movendo para a idealização de um contexto mais favorável para a sociedade buscando beneficiar grande parte da população. Assim, acredita-se que uma organização pode ser considerada o ator social capaz de criar identidade, de gerar influência e de modificar muitos contextos negativos na sua volta impactando a localidade onde está inserida de maneira relevante e profunda.

Em contrapartida, a sociedade vive alicerçada sob uma visão equivocada de consumo, recebendo estímulos de compra constantemente por meio de publicidade em todos os lugares. O mercado, aliado a fontes geradoras de informação, inserem constantemente na mídia, a ideologia de "consumo descartável", onde os produtos tornam-se obsoletos muito rapidamente dando lugar às novas tecnologias que são lançadas diariamente no mercado.

De acordo com Menuzzi e Silva (2015) a economia não pode mais deixar de considerar as questões ambientais, devendo necessariamente submeter-se às leis da natureza deixando de lado a ideia já arraigada de que o desenvolvimento econômico deve se dar ininterruptamente e "a qualquer preço". Diante das novas necessidades criadas na sociedade e aos alertas emitidos pela natureza, explorada e violada constantemente, faz-se indispensável repensar o atual modelo de expansão econômica utilizado ao redor do mundo.

Em virtude disto, torna-se necessário realizar alguns questionamentos: para onde os resíduos de pós-consumo, cada vez mais numerosos, estão sendo destinados? Ou então, quando a sociedade refletirá sobre o tamanho do impacto que os hábitos de consumo modernos e relapsos terão na manutenção dos recursos ambientais? Em síntese, "é necessário buscar soluções para os problemas globais, procurando promover mudanças de paradigmas para reconduzir a sociedade em resposta a um mundo melhor para as futuras gerações" (PINTO, p.12, 2011).

Diante do exposto, o presente estudo tem como objetivo central verificar a importância e a aplicabilidade da Gestão Ambiental aliada às ações de Responsabilidade Social realizadas por uma pequena organização atuante na área de agronegócios. O presente estudo justifica-se pelo fato de que estudos investigando a atuação neste sentido de pequenas e médias empresas, em especial situadas no interior, constituem-se raros e incipientes.

As organizações contemporâneas, independentemente do porte, representam importantes unidades de transformação e influência no meio social onde se inserem e investigar, sob a ótica dos 
stakeholders, a eficácia da sua atuação no que tange a gestão ambiental e responsabilidade social apresenta caráter inovador mediante a abordagem de uma temática atual e constantemente discutida ao redor do mundo.

Quanto à estrutura, o presente trabalho apresenta além desta introdução, nas próximas seções um referencial teórico que embasará os assuntos abordados neste estudo. Ainda, o método de pesquisa será detalhado e em seguida serão expostos os resultados levantados com a realização desta pesquisa. Por fim, trazendo as principais contribuições do trabalho tem-se a conclusão.

\section{Referencial Teórico}

Esta seção foi desenvolvida com o objetivo de embasar teoricamente os assuntos a serem desenvolvidos no decorrer deste estudo. Desta forma, a seguir, serão apresentados os tópicos referentes ao surgimento da gestão socioambiental, às organizações e a responsabilidade social e ainda às ações sociais e a prática organizacional.

\subsection{O surgimento da gestão socioambiental}

A partir da década de 1970, iniciaram-se debates sobre a evolução dos movimentos sociais e ambientais. Mais precisamente, a discussão permeava em torno dos impactos presentes e futuros, negativos e positivos relativos às questões sociais e do ecossistema, tornando-se grande fonte de motivação para mudanças organizacionais (STARIK; MARCUS, 2000). De acordo com Nascimento (2005), a associação entre a gestão social e ambiental justifica-se pelo fato de que, em geral, os danos e as ações ambientais, sejam elas preventivas ou de remediação, possuem repercussões sociais. Um exemplo claro disto é que um dano ao meio ambiente, como o derramamento de um determinado produto que polui as águas de um rio pode vir a causar também problemas na saúde das populações que utilizam-se daquelas águas bem como os pescadores que viriam a ser prejudicados devido a um problema de mortalidade dos organismos vivos que habitam o rio.

Ressalta-se ainda, que durante Revolução Industrial houve um grande desenvolvimento mundial ao qual beneficiou a economia, o desenvolvimento das indústrias e o avanço tecnológico. Em decorrência disso, a expansão social originou vários problemas sociais como o uso indiscriminado de recursos naturais entre outros, os quais até os dias atuais são amplamente discutidos (SOUZA, 2008).

Diante das preocupações com as questões socioambientais, as organizações passaram a serem pressionadas tanto pela sociedade quanto pelo governo a prestar informações sobre o modo como se relacionam frente à dinâmica de atendimento destas temáticas. Assim sendo, as organizações começaram a adotar papeis sociais distintos que consequentemente fomentaram o surgimento da responsabilidade social empresarial de maneira gradativa bem como da gestão ambiental (COUTINHO; MACEDO-SOARES, 2002). Neste sentido, o Instituto Ethos (2001) argumenta que quando uma organização adota ações de responsabilidade com cunho social e ambiental, ela não está apenas pondo em prática o seu papel social, mas também, colocando em prática atitudes que venham a promover uma transformação social positiva e cíclica na sociedade como um todo.

Corroborando neste sentido, Ferreira e Guerra (2012) inferem que as organizações passaram a atuar além de suas obrigações vislumbrando aumentar a qualidade de vida da população e ainda atendendo os interesses de seus stakeholders. Ao implementar os conceitos de sustentabilidade, o consumidor espera que as empresas, além de cumprir as suas metas financeiras, adotem papéis de agentes sociais e ambientais de transformação e desenvolvimento sustentável das localidades. Medeiros (2015) acrescenta ainda que, uma das maneiras de se obter vantagem competitiva sem comprometer muitos recursos financeiros é adotar medidas socioambientais cuja implementação e resultado se tornem atraentes aos olhos de seus consumidores e constituam-se em diferencial perante à concorrência.

Por fim, levando-se em conta que a adoção da gestão socioambiental necessita angariar resultados no presente e trazer contribuições para o futuro da organização, a sua inclusão é realizada de modo a oportunizar uma melhoria na competitividade além de aumentar a parceria com fornecedores, de 
contribuir com a conscientização da sociedade em geral buscando assumir publicamente uma postura ambientalmente responsável reforçando a imagem organizacional transmitida para a sociedade (NASCIMENTO, 2005).

\subsection{As organizações e a responsabilidade social}

Os primeiros registros de conceituação teórica a respeito de responsabilidade social dataram na década de 1950 quando a literatura formal sobre responsabilidade social corporativa aparece primeiramente nos Estados Unidos e na Europa. A inquietação daqueles que se dedicavam à pesquisa do tema, era a excessiva autonomia dos negócios e o poder que eles apresentavam sobre a sociedade, não mensurando a imensidão da responsabilidade pelas consequências possivelmente negativas das atividades que desempenhavam, como por exemplo, a degradação ambiental, a exploração do trabalho, o abuso econômico e a concorrência desleal. Em resposta aos impactos causados e buscando amenizar os aspectos negativos de sua atuação em sociedade, os empresários passaram a se envolver com atividades sociais em prol do benefício à comunidade, como uma espécie de obrigação moral (BORGER, 2001).

O termo Responsabilidade Social é interpretado de inúmeras formas. Para determinados teóricos representa uma obrigação legal já para outros, um real comportamento eticamente responsável. Em síntese, a Responsabilidade Social constitui-se no objetivo social da empresa acrescido da sua atuação econômica sendo um modelo de gestão que transpõe a barreira das leis e da filantropia (FERREIRA; GUERRA, 2012).

Robbins (2006) explana que as organizações em sua essência possuem algumas características em comum, elas têm propósitos distintos, são formadas por pessoas e desenvolvem sua própria estrutura, definindo papéis e delimitando o comportamento de seus sujeitos. Além disso, não operam sem a participação dos agentes, sendo a organização considerada um conjunto de partes que oferecem o seu melhor para sobrevivência da mesma.

As organizações privadas além da necessidade de obtenção do lucro buscam por meio de uma postura socialmente correta uma imagem positiva, de maneira a agregar valor à marca e consequentemente fidelizar os seus clientes. Ressalta-se ainda, que cada vez mais a qualidade do produto está relacionada à relação da empresa com a sociedade e seu comportamento ético e esses fatores determinam o comportamento dos consumidores (PAES, 2003). De acordo com Aguiar (2006) a responsabilidade social empresarial apresenta-se como um conceito que influencia diretamente na construção de relacionamentos éticos entre as organizações e os públicos com os quais estas mantêm contato.

Corroborando com a exposição de Aguiar, Mattar (p.24, 2001) complementa afirmando que “empresas não são simples agregados de indivíduos, e sim, grandes sistemas de tomadas de decisões, responsabilidades, compromissos, relacionamentos e objetivos, revestindo-se assim de características pessoais". Desta forma, Mattar (2001) afirma que as organizações podem ser caracterizadas como agentes morais, sendo seguidamente avaliadas e julgadas segundo diversos pontos de vista podendo inclusive modificar de maneira significativa o ambiente no qual se insere.

A empresa ao aliar estratégias com as práticas sociais gera satisfação entre seus funcionários, fidelizando clientes e gerando uma imagem positiva com todo o grupo que a empresa opera. Além disso, a responsabilidade social também gera preocupação por parte da preservação do meio ambiente e a preocupação com o bem estar das gerações posteriores (GABRIELLE, 2008).

As definições e conceituações que envolvem as questões de responsabilidade social empresarial são amplas e não possuem muitas vezes um consenso entre os gestores e a população. O tema costuma muitas vezes dividir opiniões e chega a ser visto inclusive como uma forma de promoção e mera adequação às leis impostas pelo governo por parte das organizações.

Por meio da busca pela "boa imagem" e por uma sociedade mais centrada na preservação ambiental, a organização está também preocupada com a "construção genuína de relacionamento com a comunidade, do crescimento da satisfação e motivação do colaborador, do aumento da imagem e da promoção de oportunidades de divulgação dos produtos da organização" (KOTLER; LEE, p. 178, 2005). 


\subsection{Ações sociais e a prática organizacional}

Com a acirrada concorrência observada no mercado econômico, as empresas passaram a vislumbrar no desenvolvimento de práticas sociais oportunidades de inovação e entrega de vantagens competitivas para a sociedade consumidora. As organizações estão inteirando-se dos esforços necessários para a resolução dos problemas sociais colocando à disposição das causas sociais os seus próprios planejamentos de desenvolvimento empresarial tratando-se de uma estratégia de constituição de diferenciais competitivos (RODRIGUES, 2006).

Conforme Buffara e Pereira (2003), no mundo contemporâneo dos negócios, os atributos preço e qualidade já se tornaram condições básicas e obrigatórias para o bom desempenho e avaliação das empresas no mercado consumidor. Diante disto, as organizações que desejam destacar-se vêm adicionando à sua gestão aspectos tidos historicamente como opostos no mundo capitalista: o fator econômico e o fator social.

No quadro 1 a seguir estão demonstradas as dimensões sociais que são pautadas na responsabilidade social.

\begin{tabular}{|c|c|c|}
\hline DIMENSÕES & $\begin{array}{c}\text { A DEFINIÇÃO ESTÁ } \\
\text { CODIFICADA NA } \\
\text { DIMENSÃO: }\end{array}$ & \multicolumn{1}{c|}{ EXPRESSÕES-EXEMPLO } \\
\hline $\begin{array}{c}\text { Dimensão } \\
\text { ambiental }\end{array}$ & Meio-ambiente & $\begin{array}{l}\text {-Um ambiente mais limpo } \\
\text {-Hospedagem ambiental } \\
\text {-Preocupações ambientais inseridas no } \\
\text { negócio }\end{array}$ \\
\hline $\begin{array}{c}\text { Dimensão } \\
\text { social }\end{array}$ & $\begin{array}{c}\text { Relação entre as } \\
\text { empresas e a sociedade }\end{array}$ & $\begin{array}{l}\text {-Contribuir para uma sociedade melhor } \\
\text {-Preocupações ambientais inseridas no } \\
\text { negócio } \\
\text {-Considerar o espectro do seu impacto } \\
\text { nas comunidades }\end{array}$ \\
\hline $\begin{array}{c}\text { Dimensão } \\
\text { econômica }\end{array}$ & $\begin{array}{l}\text { Aspectos ocioeconômicos } \\
\text { financeiros, incluindo a } \\
\text { responsabilidade social }\end{array}$ & $\begin{array}{l}\text {-Contribuir para o desenvolvimento } \\
\text { econômico } \\
\text {-Preservar a geração de lucro } \\
\text {-Operações de negócio }\end{array}$ \\
\hline Dimensão do & Ações não prescritas por & $\begin{array}{l}\text {-Baseado em valores éticos } \\
\text {-Para além das obrigações legais } \\
\text {-Voluntariamente }\end{array}$ \\
\hline voluntariado & lei & \\
\hline
\end{tabular}

Quadro 1 - Dimensões Sociais que abrangem a responsabilidade social

Fonte: Dahlsrud (p.4, 2006)

Nas dimensões sociais que abrangem a responsabilidade social observadas no Quadro 1, é possível perceber que algumas atitudes simples são possíveis de serem realizadas no âmbito ambiental de atuação das organizações, como por exemplo, a responsabilidade com o meio ambiente, a preservação e a conservação da fauna e da flora. Quanto à dimensão social, é possível realizar ações que contribuam com o aprimoramento de uma sociedade melhor e mais justa, bem como adequar campanhas de preocupação social que venham a despertar certo impacto positivo na sociedade (DAHLSRUD, 2006).

Nesse sentido, o mesmo autor ressalta que a responsabilidade social empresarial nada mais é do que as obrigações que uma empresa assume ao realizar ações com o intuito de proteger e melhorar o bem-estar da sociedade segundo os seus próprios interesses. Corroborando com essa ideia, Ashley (2005) afirma que existindo um envolvimento entre os parceiros para a definição das estratégias da organização ocorre o comprometimento mútuo perante as metas estabelecidas, neste caso, uma boa 
relação entre funcionários, fornecedores e clientes por meio de uma adequada comunicação faz-se imprescindível para que seja aplicada a responsabilidade social.

\section{Método}

O método utilizado na concretização desta pesquisa classifica-se, com base em seus objetivos como um estudo de caso descritivo. De acordo com Gil (2009) estudo de caso é um tipo de pesquisa amplamente utilizada que caracteriza-se pelo estudo exaustivo e profundo de um ou mais objetos, permitindo o alto detalhamento e conhecimento, buscando analisar um fenômeno contemporâneo dentro de um contexto específico.

Buscando a viabilização deste estudo, considerou-se uma pequena organização voltada ao setor agroindustrial localizada em uma cidade do interior do Rio Grande do Sul como objeto de pesquisa, a qual contribuiu com dados e informações para elaboração do presente artigo. Como instrumento de coleta de dados, foi aplicado um questionário semiestruturado de cunho exploratório descritivo junto aos atores pertencentes ao convívio da empresa em questão, no período que compreendeu o mês de outubro de 2012, para tal consideraram-se a percepção de funcionários, fornecedores, clientes e sociedade da pequena cidade.

Faz-se relevante salientar que o critério de escolha da empresa, objeto de estudo deste artigo, justifica-se devido ao interesse dos pesquisadores em verificar como se dão as tratativas de gestão da responsabilidade socioambiental em organizações do ramo agroindustrial, importante setor de desenvolvimento econômico e social da região onde a empresa sedia-se. Além disso, comumente observam-se ações vindas de organizações sediadas em grandes centros de localização geográfica sendo ainda pouco comum visualizar efetivas ações de responsabilidade social e ambiental advindas de empresas situadas em pequenos centros econômicos.

Por fim, o instrumento de pesquisa contava com a exposição de algumas variáveis pertinentes ao tema confrontando-as com a realidade vivenciada pela organização estudada. De posse dos dados, prosseguiu-se com a análise dos mesmos que se deu por meio de transcrição e posterior análise de conteúdo sob a ótica qualitativa.

\section{Análise e Discussão dos Resultados}

Levando-se em consideração a aplicação do estudo de análise de gestão ambiental com enfoque na responsabilidade social, realizado em uma pequena organização voltada ao setor agroindustrial, em uma cidade localizada no interior do Rio Grande do Sul, têm-se por meio da aplicação do instrumento de coleta de dados uma breve caracterização do perfil da amostra pesquisa bem como a percepção dos funcionários, fornecedores, clientes e sociedade a respeito de cinco variáveis que foram expostas a estes.

Sendo assim, o Quadro 2 a seguir dará início à exposição das informações obtidas com a aplicação da pesquisa demonstrando de forma sucinta os segmentos de público entrevistados e a forma como estes responderam e tiveram acesso à pesquisa.

\begin{tabular}{|l|c|l|}
\hline CLASSIFICAÇÃO & $\begin{array}{c}\text { No DE } \\
\text { FORMA DE } \\
\text { INTERNOS }\end{array}$ & \multicolumn{1}{c|}{$\begin{array}{c}\text { COLETA } \\
\text { QUESTIONÁRIOS }\end{array}$} \\
\hline Funcionários & $\mathbf{1 7}$ & - \\
\hline EXTERNOS & 17 & Pessoalmente \\
\hline Fornecedores & $\mathbf{1 8 6}$ & Via e-mail \\
\hline Clientes & 8 & Pessoalmente \\
\hline Sociedade & 130 & Pessoalmente \\
\hline TOTAL & $\mathbf{2 0 3}$ & - \\
\hline
\end{tabular}

Quadro 2 - Classificação dos entrevistados e formas de coleta dos dados

Fonte: Elaborado pelos autores 
Por meio da visualização do Quadro 2 tornou-se possível identificar a quantidade de pessoas em que fora aplicado o estudo bem como a classificação de composição da amostra. Desta forma, de um total de 203 entrevistados, participaram da pesquisa 17 funcionários, 8 fornecedores, 48 clientes e 130 pessoas entrevistadas aleatoriamente na sociedade onde a empresa, objeto desta pesquisa, está inserida. Cabe salientar que todas as aplicações deram-se pessoalmente com exceção dos fornecedores, que por questões de viabilidade optou-se por utilizar uma conta de e-mail para proceder com a aplicação.

Nos próximos tópicos, a percepção dos entrevistados acerca de cinco variáveis passíveis de investigação a respeito da temática proposta neste artigo serão evidenciadas. As variáveis em questão são: reconhecimento da empresa; ações sociais e o conhecimento prático; ações sociais e a prática voltada à sociedade; grau de satisfação das ações sociais segundo a sociedade e percepção e modificações das ações.

\section{a) Reconhecimento da empresa}

As organizações passam cada vez mais a preocupar-se com a imagem que formulam a seu respeito e principalmente com aquela que é percebida pelos seus clientes. Isto porque, a transmissão de uma imagem positiva alicerçada em valores sólidos e efetivas contribuições com a sociedade pode gerar além de um bom conceito, a possibilidade de efetivação de novos e promissores negócios representando ainda, um importante diferencial competitivo frente à concorrência.

Desta forma, de acordo com a percepção dos respondentes indagados na pesquisa, neste primeiro momento, em especial os funcionários, a empresa é reconhecida no mercado pelo entrosamento na equipe, bom relacionamento com o proprietário, pelos eventos de integração, assim como pela preocupação da empresa com o bom uso e descarte adequado de materiais inflamáveis. Já na opinião dos seus fornecedores, a empresa possui reconhecimento principalmente no que diz respeito ao suporte oferecido.

Na opinião dos clientes, a organização além de oferecer suporte quando necessário, é reconhecida pela sua solidez no mercado e bom relacionamento mantido pelo proprietário com os clientes frequentadores da empresa. Devido ao fato de trabalhar com a comercialização de produtos tidos como "agressores" do meio ambiente, como por exemplo, defensivos agrícolas, a empresa procura sempre informar os clientes a respeito do uso e manuseio adequado destes. Além disso, ressaltou-se por parte dos entrevistados, que a empresa prioriza a explanação no momento da venda de informações minuciosas que geralmente estão contidas nos rótulos das embalagens, auxiliando assim, o cliente sobre a forma correta de consumo e descarte dos resíduos de pós-uso.

Na opinião dos entrevistados que compõe o grupo da sociedade, a empresa já é reconhecida na localidade também pela solidez de mercado e bom históricos de relações com clientes, fornecedores e comunidade.

\section{b) Ações sociais e o conhecimento prático}

De maneira geral, dentre os segmentos classificatórios de respondentes, observou-se que a maioria apontou que a empresa costuma adotar atitudes responsáveis, mas que, um pequeno público acredita que a empresa não executa satisfatoriamente algumas ações, deixando por muitas vezes de dar continuidade a determinados trabalhos iniciados.

Quanto ao tratamento de seus funcionários, a organização desenvolve alguns eventos, como por exemplo, jantares, palestras, além de fornecer plano de saúde e suporte aos funcionários no que tange à algumas reivindicações. Logo, quanto à questão do suporte, é possível relatar que muitos dos respondentes da pesquisa expuseram que o próprio proprietário da organização é preocupado quanto ao bem estar de seus funcionários, pois procura auxiliá-los sempre que estes necessitam, tanto para questões pessoais como profissionais.

Já os fornecedores, apontam que a empresa sempre que pode realiza jantares e participa de eventos promovendo-os. Quanto aos clientes, estes afirmaram também que a empresa promove jantares como 
forma de integração, outra atitude passível de destaque evidenciada é o respeito ao meio ambiente e o fornecimento de suporte por meio de prestação de informações relevantes aos seus clientes, além do auxílio prestado à sociedade por meio de doações sempre que possível. Por fim, no que se refere à percepção da sociedade, a empresa também realiza jantares aos clientes, promove o respeito ao meio ambiente participando ainda de eventos.

\section{c) Ações sociais e a prática voltada à sociedade}

A responsabilidade social também é uma prática em benefício à sociedade, pois muitas vezes pequenas atitudes que venham a favorecer pequenos grupos, podem gerar grandes avanços e transformações sociais, como a disseminação do "exemplo" e, em consequência, a implantação de mais outras atitudes, oriundas muitas vezes de outras organizações, visando o fomento a uma sociedade mais agradável de viver.

Portanto, quando indagados a respeito desta variável, os funcionários afirmaram que a empresa se mobiliza realizando promoções de eventos, doações de mantimentos a entidades carentes, e promovendo o respeito ao meio ambiente. Na opinião dos fornecedores, a empresa procura participar dos eventos, muitas vezes participando ativamente da organização e divulgação destes. Já para os clientes, a empresa procura sempre disseminar o respeito ao meio ambiente por meio de campanhas de conscientização, além de realizar doações. Finalizando, na percepção da sociedade, a contribuição principal da empresa quanto a este quesito é o apoio aos eventos e a preocupação com o meio ambiente.

\section{d) Grau de satisfação das ações sociais segundo a sociedade}

Conforme Ferrell, Fraedrich e Ferrell (2001), a sociedade acredita que o governo em parceria com as empresas privadas atuam sobre a comunidade na busca de um bom desenvolvimento da sociedade em prol do aumento na qualidade de vida. Essa expectativa considera que as empresas contribuem com as comunidades locais de acordo com as suas possibilidades. Porém, hoje ainda são poucas as instituições que pensam no desenvolvimento sustentável pautando principalmente a sua forma de atuação e desenvolvimento alicerçada nestes valores.

Neste sentido, a empresa apresenta ações, colocando-as em prática no que diz respeito à responsabilidade social e também à questões ambientais voltadas para a sociedade onde se encontra inserida, logo, quando questionados a respeito, todos os grupos compreendidos na amostra demonstraram que a organização detém uma postura sólida e atuante quanto a realização de ações sociais. Este comportamento justifica-se em especial pela atuação e auxílio junto aos grupos mais carentes da localidade e também pela promoção e apoio a eventos importantes ao desenvolvimento do local. As percepções obtidas demonstraram que a satisfação para com as ações desenvolvidas pela empresa objeto desta pesquisa classificam-se como satisfatórias.

\section{e) Percepção e modificação das ações}

A última variável a ser analisada diz respeito à percepção dos entrevistados e também a possíveis modificações que poderiam vir a ocorrer buscando um aperfeiçoamento da atuação desta empresa para com as questões sociais. Neste sentido, é possível perceber outras ações sugeridas para serem incorporadas quanto à relação comercial da empresa.

Muitos respondentes apesar de estarem satisfeitos com a atuação da empresa, ainda acreditam que as ações sociais realizadas poderiam ser ampliadas. Os funcionários gostariam que fosse implantado um plano de carreira juntamente com uma espécie de auxílio qualificação. Já os fornecedores, demostraram a necessidade da participação e da promoção de eventos de forma mais assídua e ampliada. Neste sentido, os clientes, apontam a necessidade em participar de eventos, juntamente com a criação de pequenos cursos voltados a sanar duvidas comumente apresentadas pelos produtores rurais. Já, segundo a sociedade, a necessidade de cursos de capacitação, que 
envolvam a sociedade, principalmente no que tange o manuseio de produtos agrícolas, salientando o fato de que a região é caracterizada pela base econômica ter a sua sustentação principalmente pautada em atividades agrícolas.

Neste sentido, de acordo com a opinião dos respondentes e segundo algumas atitudes possíveis de serem aplicadas dentro da organização, elaborou-se um plano de ação que contempla os quatro grupos participantes da pesquisa e que constituem-se em agentes de interação direta com a organização estudada: os funcionários, fornecedores, clientes e a sociedade. Corroborando com o exposto, traz-se a ideia de que, ao adicionar às suas competências básicas uma conduta ética e socialmente responsável, as empresas conquistam o respeito das pessoas e das comunidades atingidas por suas atividades, tanto no engajamento de seus funcionários como na preferência dos consumidores pela manutenção de relações comerciais (ETHOS, 2001).

Dando seguimento, Grajew (p.1, 2005) argumenta que a responsabilidade social está atrelada a todas as formas de relação, como "em todas as suas ações, em todas as suas políticas, em todas as suas práticas, em todas as suas relações." Deste mesmo modo, isso significa que a responsabilidade social da empresa dá-se em relação à comunidade onde está instalada, aos seus empregados, aos seus fornecedores, ao meio ambiente (GRAJEW, 2005).

Para melhor demonstrar os resultados obtidos na pesquisa de responsabilidade social junto aos atores internos e externos, elaborou-se um plano de ações sucinto conforme se pode observar no Quadro 3 a seguir. O mesmo evidencia algumas ações possíveis de serem adotadas visando melhorar a atuação social da empresa para com os grupos entrevistados neste estudo que constituem-se nos principais atores com os quais a empresa possui relacionamento.

\begin{tabular}{l|l|}
\hline PLANOS DE AÇÃO SUGERIDOS \\
\cline { 2 - 3 } & - Desenvolvimento de cursos profissionalizantes e capacitações \\
\hline -Implantação de um seguro de vida aos funcionários \\
\hline -Criação do Código de Ética da empresa \\
\hline -Participação em campanhas de doação (de sangue, de agasalho, de alimentos etc.) \\
\hline -Separação do lixo para reciclagem \\
\hline -Plano de Previdência Privada \\
\hline $\begin{array}{l}\text {-Eventos de integração com a comunidade incluindo atrações para as famílias } \\
\text { particularmente em datas comemorativas }\end{array}$ \\
\hline -Desenvolvimento de ações de Preservação do Meio Ambiente \\
Quadro 3 - Plano de ações sociais sugeridas.
\end{tabular}

Fonte: Elaborado pelos autores

Quanto aos funcionários, o Quadro 3 destaca por meio da elaboração de um plano de ações específico, a importância da implantação de um plano de carreira, cursos profissionalizantes, oferta de um seguro de vida (fornecendo maior segurança aos familiares, tanto em caso de acidente de trabalho, como também nos demais casos de danos permanentes à saúde). A participação mais assídua da empresa na promoção de eventos em sociedade e a concepção de um código de ética próprio da empresa foram elencados como pontos passíveis de desenvolvimento de planos de atuação.

O plano de sugestões desenvolvido com base na percepção dos entrevistados inclui também, a adoção de algumas campanhas de doação de sangue, roupas, alimentos e demais itens que sejam necessários ao bem-estar da sociedade. Já com relação às ações que priorizem a preservação do meio ambiente, a organização deve usufruir de latas de lixo no interior do ambiente empresarial e que estejam devidamente identificadas quanto à destinação correta dos detritos. Levando-se em consideração a existência de uma oficina na empresa, ocasionando a geração de diversos tipos de materiais descartáveis com tratamento específico de descarte, sugeriu-se que haja o investimento na separação de resíduos convencionais e corrosivos. Salienta-se que o cuidado com a separação existe, mas não há um meio de coleta diferenciado que garanta o destino e extinção corretos dos resíduos oriundos das atividades na oficina.

Quanto às embalagens de materiais inflamáveis e de defensivos agrícolas, ocorre a separação e envio a um estabelecimento regulamentando que procede com a prática da "tríplice-lavagem" 
removendo todo e qualquer tipo de resíduo tóxico do interior das embalagens. No entanto, buscandose aprimorar o processo, se sugere que a empresa invista em armazenamento adequado das embalagens que ainda não sofreram o processo de limpeza e que recém retornaram das propriedades rurais, buscando uma diminuição do risco de contaminação de recursos humanos e materiais.

Finalmente, como exposto acima, salienta-se que a empresa pode também adotar atitudes permanentes de preservação ambiental, reforçando e demostrando junto à sociedade a importância da preservação da natureza e uso consciente dos recursos naturais buscando a garantia da sobrevivência das futuras gerações, atuando tanto no meio organizacional como externo.

\section{Conclusões}

Como explanado até o momento, a responsabilidade social e ambiental não está pautada apenas no desenvolvimento de ações de grande e complexo porte. A atuação das organizações pode se dar de forma simples e pequena, porém com grande importância e impacto na cultura organizacional. Porém, mesmo que muitas das ações sociais sejam de fácil compreensão e possíveis de serem implantadas, muitas organizações ainda têm resistência quanto à sua adoção (ETHOS, 2001).

Muitas vezes a aplicação de pequenas atitudes por parte das organizações, além de agregar diversos benefícios e impactos positivos para as gerações posteriores, como a preservação ambiental, valorização social dos indivíduos, maior qualidade de vida, ainda geram melhoria da imagem organizacional, aumentando a sua capacidade competitiva por meio de uma imagem pró ativa, conforme o que consta no papel social desenvolvido por cada organização.

Portanto, junto à responsabilidade social e ambiental, torna-se possível citar também a importância do papel social transmitido pela empresa. Neste sentido, o papel social nada mais é do que a postura ética, os direitos e deveres que uma organização têm e pode proporcionar em seu meio interno e externo, já a responsabilidade social norteia todas as ações que a empresa pode promover procurando ir além do básico, buscando gerar benefícios e gerando desenvolvimento à sociedade (JORGE; CARVALHO, 2008).

A responsabilidade social e ambiental de acordo com Kirschner (2006) é uma forma de agregar valor à organização, pois funcionários satisfeitos acabam agregando maior qualidade em sua produção, assim como clientes satisfeitos acabam se tornando fiéis à organização e consecutivamente trazem mais clientes por meio de indicações. A sociedade, por sua vez, satisfeita com a atuação da empresa acaba projetando uma imagem positiva da mesma para o contexto mercadológico.

No entanto, algumas mudanças já estão ocorrendo no cenário econômico quanto ao consumo sustentável. Isto deve-se aos muitos consumidores que modificaram a sua maneira de pensar e de consumir, buscando adquirir produtos ecologicamente sustentáveis e que apostem em ações voltadas a "implementação de processos produtivos mais limpos, inovando insumos de produção e materiais, embalagens e meios de distribuição, e engajando-se efetivamente em movimentos ecológicos e em prol do desenvolvimento sustentável" (RIBEIRO, VEIGA, p.5, 2011).

Pode observar-se ainda, como atitudes simples de serem adotadas e apoiadas sobre o comportamento da sociedade, as ações cotidianas e comuns ao dia a dia das pessoas, que não exigem grandes mudanças e que caracterizam-se pela aplicabilidade lógica em nossas residências por meio da promoção de hábitos sustentáveis como, por exemplo, a separação do lixo. Como tornou-se possível observar com este estudo, a atuação das empresas mostra-se, de forma engajada e no caminho adequado para a implementação de rotinas mais social e ambientalmente adequadas, precisando apenas de mais fôlego de mão-de-obra própria ao desenvolvimento das ações e diversificação de atuação.

O aperfeiçoamento da atuação foi neste caso, salientada pelos atores pesquisados. Assim como em diversos casos, a atuação organizacional limita-se à execução do básico, não trazendo atitudes e ações inovadoras e que impactem com mais veemência na sociedade onde se inserem. Contudo, acredita-se que as transformações estão começando a se dar de forma mais aplicada e consciente visto que já é possível observar diversas respostas sociais e ambientais que culminam em um acréscimo de reflexão por parte das empresas quanto ao papel e à influência que possuem na sociedade. 
Sintetizando, procura-se não só um novo paradigma de reconstrução e de reengenharia de processos, produtos, serviços e atitudes por parte das indústrias, e sim, uma reorganização da sociedade, buscando um ambiente mais limpo e sustentável, onde muitas vezes pequenas atitudes não são colocadas em prática por descuido, cultura, falta de hábito, falta de tempo, pouca influências recebidas pelo meio em que habitamos. Muitas vezes procuramos achar culpados fora de casa quando o que estamos procurando modificar é uma cultura própria e mais sustentável para se viver. Mudanças e respostas devem ocorrer de dentro para fora de nossos lares, para depois sim exigir-se um posicionamento melhor por parte das indústrias ao buscar um ambiente mais limpo e ecologicamente sustentável.

Por fim, o que se busca é um comportamento mais positivo sobre o comportamento do indivíduo como consumidor. Busca-se com isso mudanças a respeito do uso frequente de produtos e serviços ecologicamente corretos, da economia de recursos comuns (agua e energia), da utilização cuidadosa de materiais e equipamentos até o fim real da sua vida útil, da reutilização de produtos por meio de reciclagem e também da correta destinação de materiais ao final do ciclo de vida destes. Por meio de comportamentos pontuais e simples, seja por parte da população ou das organizações, espera-se uma nova perspectiva para o rumo da sociedade.

\section{Referências}

AGUIAR, L. S. de. Responsabilidade social empresarial na prática: o papel da comunicação organizacional. Novos Olhares, v. 17, 2006.

ASHLEY, P. A. Ética e responsabilidade social nos negócios. São Paulo: Saraiva, 2005.

BORGER, F. G. Responsabilidade Social: Efeitos da atuação social na dinâmica empresarial. Tese (Doutorado) - Universidade de São Paulo. São Paulo, 2001.

BUFFARA, L. C. B.; PEREIRA, M. F. Desenvolvimento sustentável e responsabilidade social: Um estudo de caso no grupo O Boticário. Revista de Ciências da Administração, v.5, n. 9, jan./jul. 2003.

COUTINHO, R. B. G.; MACEDO-SOARES, T. D. A. Gestão estratégica com responsabilidade social: arcabouço analítico para auxiliar sua implementação em empresas no Brasil. Revista de Administração Contemporânea, v. 6, n. 3, 2002.

DAHLSRUD, A. How corporate social responsibility is defined: an analysis of 37 definitions. Corporate Social Responsibility and Environmental Management, 2006.

ETHOS- INSTITUTO ETHOS. Guia de elaboração de relatório e balanço anual de responsabilidade social empresarial. São Paulo: Instituto Ethos, 2001.

FERREIRA, B. S.; GUERRA, J. A. de P. Responsabilidade Socioambiental: um olhar sistêmico em uma organização estatal. Revista Gestão \& Conhecimento, Ed. Especial, nov. 2012.

FERRELL, O. C.; FRAEDRICH, J.; FERRELL, L. Ética Empresarial: dilemas, tomadas de decisões e casos (tradução). Rio de Janeiro: Reichmann \& Affonso, 2001.

GABRIELLE, J. Responsabilidade Social Corporativa: mais do que marketing ou mera filantropia, é estratégia de sustentabilidade. Junho, 2008. Disponível em : $<$ http://www.administradores.com.br/informe-se/artigos/responsabilidadesocial-corporativa-maisdo-que-marketing-ou-mera-filantropia-e-estratégia-de sustentabilidade/23271/>. Acesso em: 17 mai. 2012.

GIL, A. C. Como elaborar projetos de pesquisa. 4 ed. São Paulo: Atlas, 2009.

GRAJEW, O. Filantropia e Responsabilidade Social. 2005. Disponível em: <http://www.Filantropia .org/artigos/oded_grajew.htm>. Acesso em: 17 ago. 2012.

JORGE, N.; CARVALHO, E. SOCIOLOGIA: Papel Social e Estatuto. Escola Superior de 
Gestão de Santarém. 2008.

KIRSCHNER, A. M. Sociologia da empresa e responsabilidade social das empresas. Nueva Sociedad, Buenos Aires, n. 202, mar./abr. 2006.

KOTLER, P.; LEE, N. Corporate Social Responsibility: doing the most good for your company and your cause. United States: John Wiley e Sons Inc, 2005.

MATTAR, F. N. Pesquisa de Marketing. 3 ed. São Paulo: Atlas, 2001.

MEDEIROS, M. do. S. B. et al. Gestão ambiental e sustentabilidade: Um estudo de caso na Agência do Banco do Brasil de Alagoa Nova/PB. Revista Eletrônica em Gestão, Educação e Tecnologia Ambiental, v. 19, n. 3, 2015.

MENUZZI, T. S.; SILVA da, L. G. Z. Interação entre economia e meio ambiente: uma discussão teórica. Revista Eletrônica em Gestão, Educação e Tecnologia Ambiental, v. 19, n. 4, 2015.

MILANI FILHO, M.; CORRAR, L. J.; MARTINS, G. A. O voluntariado nas entidades filantrópicas paulistanas: $\mathrm{O}$ valor não registrado contabilmente. Contabilidade, Gestão e Governança, América do Norte, 6, out. 2009. Disponível em: <http://www.cgg-amg.unb.br/index.php/contabil/ article/view/200>. Acesso em: 6 abr. 2012.

NASCIMENTO, L. F. Gestão Socioambiental Estratégica: A percepção de executivos de pequenas e médias empresas americanas. In: ENANPAD, Brasília. Anais... Brasília, Brasil, 2005.

PAES, A. A Responsabilidade Social Empresarial (RSE): espaço de intervenção profissional do Serviço Social. Trabalho de Conclusão de Curso. Faculdade de Serviço Social da PUC-SP, São Paulo, 2003.

PINTO, M. J. Discurso, implícitos e ideologia: As ONGs e a visão arcaica da relação entre o público e o estatal. Trabalho apresentado na Compós, 2011.

ROBBINS, S. P. Administração: Mudanças e Perspectivas. 3 ed. Rio de Janeiro: Saraiva, 2006.

RODRIGUES, A. L. Modelos de gestão e inovação social em organizações sem fins lucrativos: divergências e convergências entre Nonprofit Sector e Economia Social. In: ENANPAD, Salvador. Anais...Salvador, Brasil, 2006.

RIBEIRO, J. A.; VEIGA, R. T. Proposição de uma escala de consumo sustentável. Revista de Administração (RAUSP), São Paulo, v.46, n.1, p.45-60, jan./fev./mar. 2011.

SOUZA, W. J. Responsabilidade social Corporativa e o Terceiro Setor. Apostila preparadora para o curso de administração na modalidade distância, 2008. Brasília: UNB, 2009. Disponível em: $<$ http://uab.unb.br/admeadnorte/cours e/view.php?id=79>. Acesso em: 17 mai. 2012.

STARIK, M.; MARCUS, A. New research directions in the field of management of organizations in the natural environment. Academy of Management Journal, v.43, n. 4, p. 539 - 546, 2000. 